\title{
Bilateral Tibial Xanthoma in a Normolipidemic Patient-Report of a Rare Case with Review of Literature
}

\author{
Vallabhaneni Kalyan Chakravarthi, E. Aruna, Damera Naveen Chandra Rao, Diddi Ranga Rao
}

Department of Pathology, Dr.PSIMS \& RF, Chinna Avutapalli, India.

Email: kalyancv74@yahoo.com

Received January $5^{\text {th }}, 2012$; revised February $18^{\text {th }}, 2012$; accepted March $24^{\text {th }}, 2012$

\begin{abstract}
Xanthoma of bone is a rare benign bone disorder. It radiologically presents as a lytic lesion, often with cortical expansion or disruption, mimics primary bone tumors and metastatic lesions. Histopathological study gives the definitive diagnosis. Xanthoma of bilateral tibia in a normolipidemic patient is rare and not yet reported in literature. Here with we present one such rare case, with review of literature.
\end{abstract}

Keywords: Xanthoma; Normolipidic; Tibia; Lytic Lesion

\section{Introduction}

Xanthoma of bone is an exceedingly rare benign primary bone tumor. Intraosseous xanthomas are lytic, expansile lesions composed of lipid-laden histiocytes, [1] often seen in patients with hyperlipidemic conditions [2,3]. Xanthomas are histologically characterized by mononuclear macrophage-like cells, abundant foam cells, and multinucleated giant cells. Occasionally, spindle cells are present, which has led investigators to include this lesion as a subset of benign fibrous histiocytoma (BFH) of bone [4]. One 45 years old lady who presented to our institution was discovered to have an intraosseous xanthoma in both tibia in the absence of hyperlipidemia. The lesion showed abundant giant cells, mononuclear cells, foam cells and cholesterol crystals. We present this rare case of intraosseous xanthoma, along with review of literature.

\section{Case Report}

A 45 year old housewife presented with swelling in upper $1 / 3^{\text {rd }}$ of both lower limbs, pain \& inability to walk on left leg following a slip \& fall. On examination there was a diffuse swelling and tenderness in left leg. Patient was asymptomatic before fall and hence duration of the swelling could not be determined. On investigating, $x$-ray of left leg revealed fracture of both bones of left lower limb and an osteolytic lesion in the proximal part of left tibia (Figure 1). X-ray of right leg showed an osteolytic lesion in the upper $1 / 3^{\text {rd }}$ of tibia (Figure 2). MRI-T1, T2 \& FATSAT of Lt leg showed multiseptate lesion involving epiphyseo-metaphyseal region with extension upto proximal diaphysis with enhancing signal in the lesion at

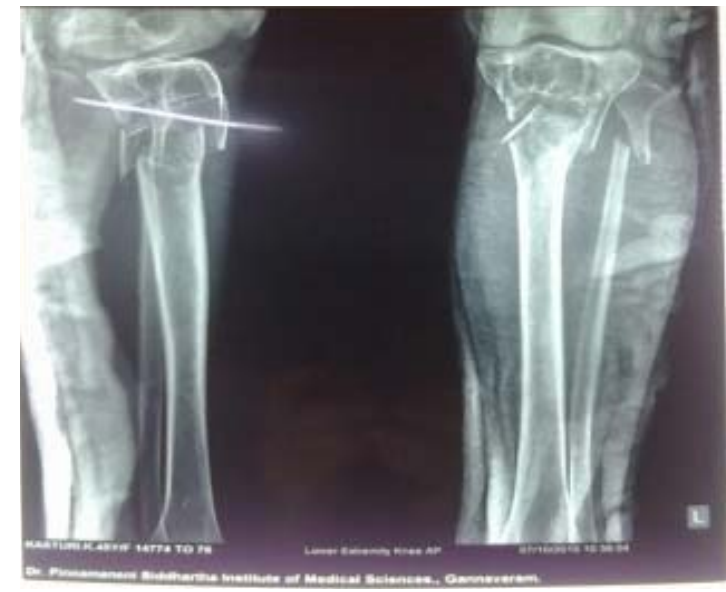

Figure 1. X-ray of left leg showing fracture of both bones and an osteolytic lesion in proximal tibia.

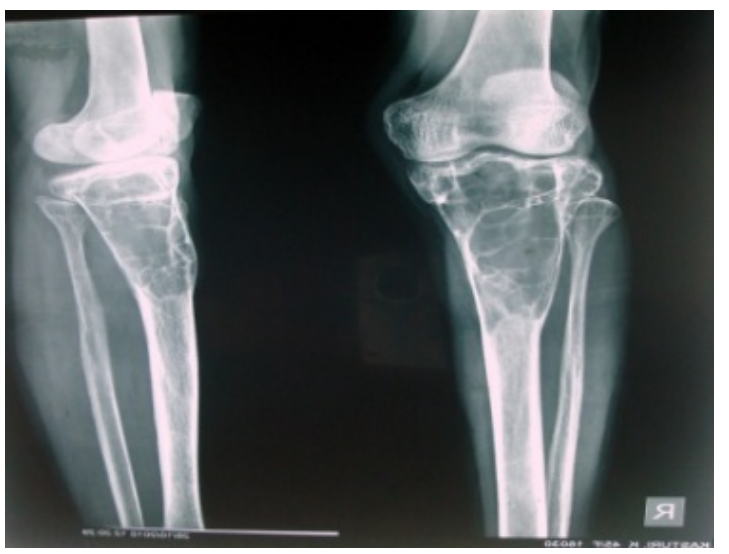

Figure 2. X-ray of right lower leg showing osteolytic lesion in proximal part of tibia. 
fracture site, suggesting Haemorrhage. MRI-T1, T2 \& FATSAT of right Leg showed multiseptate lesion of epiphyseo-metaphyseal region with extension up to proximal diaphysis on right side. No obvious extracortical soft tissue extension was seen, normal joint space \& articular surface was maintained. The patient was submitted for Biochemical investigations and the results showed, Serum calcium $-9.5 \mathrm{mg} / \mathrm{dl}$ (8.5 - 10.5), Serum phosphorus $-4 \mathrm{mg} / \mathrm{dl}(3.4$ - 5), Alkaline phosphatase $-65 \mathrm{IU} / \mathrm{L}$ \& Parathyroid hormone levels $-24 \mathrm{pg} / \mathrm{dl}(10-55)$ were within normal limit. No abnormality was noted in remaining other systems. Following this, curetting biopsy of left Tibial lesion with bone graft and nailing was done and specimen was sent for histopathological opinion. The bony and soft tissue bits were gray to yellow in colour, and histopathologically showed bundles of hyalinized collagen fibers traversed by small \& large blood vessels lined by endothelial cells, non specific granulation tissue at the periphery, Cholesterol clefts \& giant cells at focal areas. No cyst was identified in multiple sections studied. To rule out haemangioma venous doppler of left \& right Lower limb was done which was normal. This was followed by Fine needle aspiration of right tibial lesion which yielded 3 cc of straw coloured fluid and this fluid showed few cells consisting of foamy macrophages and occasional lymphocytes, neutrophils in a proteinaceous background. Following this, curettage biopsy and bone graft of the right tibial lesion was done and the tissue was sent for histopathological opinion. Biopsy constituted of multiple bony and soft tissue bits and these showed sheets of foamy histiocytes interspersed with occasional inflammatory cells, in a fibrocollagenous stroma. There were abundant cholesterol clefts with giant cells around them and Cholesterol clefts between bony spicules were seen (Figures 3). Special stains were done, and Vangieson's stain showed delicate collagen in the interstitium, whereas Reticulin stain was negative, no blood vessels or individual cell reticulin was seen. Schultz reaction on frozen section was done which was weakly positive, showing light blue green cholesterol crystals. Polarizer on frozen sections showed focal birefringent cholesterol crystals as needles \& block brightness. Histologically benign fibrous histiocytoma and non ossifying fibroma were considered as differential diagnosis. The benign fibrous histiocytoma shows spindle cells arranged in storiform pattern which was lacking in our case, where as non ossifying fibroma shows cellular fibrous tissue arranged in storiform patterns, scattered osteoclasts, foamy \& hemosiderin laden macrophages and sometimes bizarre nuclei, and all these features were lacking in our case. And thus depending on the above findings and radiological and biochemical findings the final diagnosis was rendered as primary tuberous xanthoma of both tibial bones.
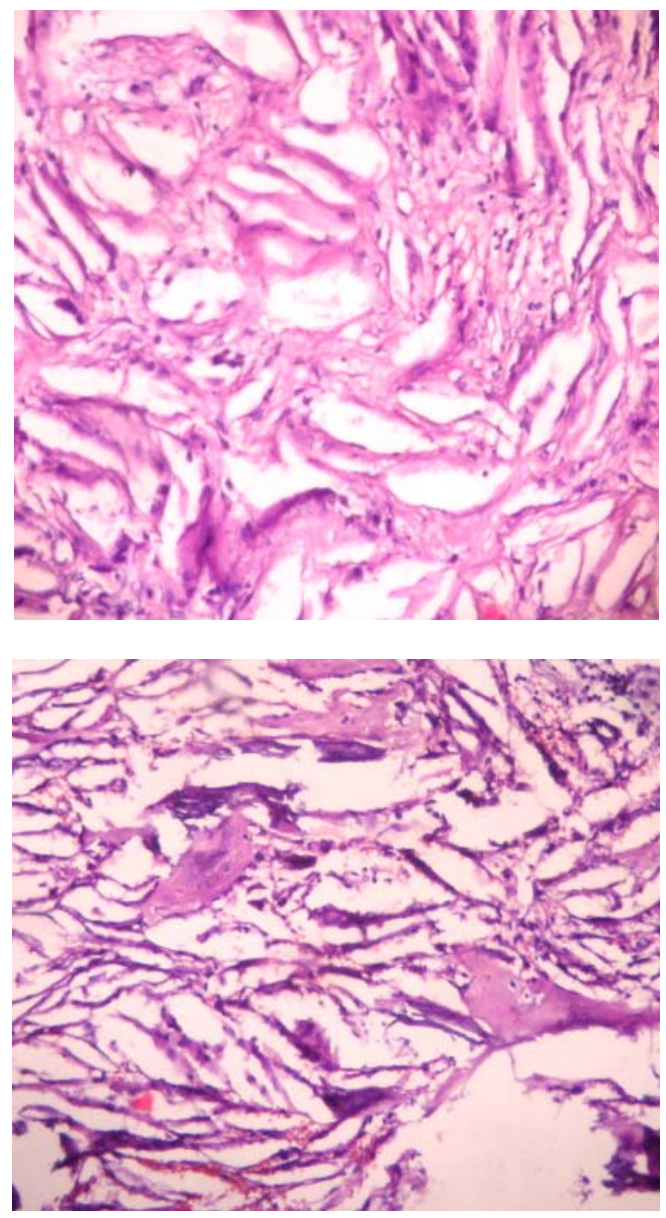

Figure 3. Abundant cholesterol clefts with giant cells around them. Sheets of foamy macrophages interspersed with occasional inflammatory cells. There are also bony spicules between cholesterol clefts.

Seeing the histology of the samples received, the patient was submitted for lipid profile and the family members were also advised lipid profile study. The lipid levels of the patient were within the normal limit, and the son of the patient who was the only relative available refused to cooperate.

\section{Discussion—Review of Literature}

Xanthoma is a tumour like collection of foamy histiocytes. They may occur in all five subtypes of essential hyperlipidemia, in disease states associated with secondary hyperlipidemia (e.g., primary biliary cirrhosis, diabetes mellitus) and occasionally in the normolipidemic state. Usually xanthomas occur in the skin and subcutis, but occasionally they involve deep soft tissue such as tendon or synovium and bone. Cutaneous xanthomas are designated into 5 types, 1) Eruptive, 2) Tuberous, 3) Tendinous xanthomas, 4) xanthelasma, 5) Plane xanthoma [5].

Xanthoma of bone is an exceedingly rare tumor $(<70$ cases reported in the appendicular and axial skeleton till 
2011 December. It is often seen in association with hyperlipidemic conditions [2,3] and also rarely in normolipidemic condition [6]. In normolipidemic condition the presenting symptom may be pain without a skin lesion. Xanthoma are usually asymptomatic, and identified incidentally. In our case also, the patient was normolipidemic, asymptomatic and xanthoma was an incidentally finding.

With respect to its anatomic distribution, xanthoma has been described in several intraosseous locations: femur; [1,8,9], skull; [10-18] phalanx; [7] ribs; [1,10] calcaneus; [1,10,19-22] pelvis; [1] mandible; [23-25] sacrum; [26] ulna; [27] radius; [1] humerus; [1] spine [1,28, 29], Tibia. [7] Bertoni F. et al. [1] reported 21 cases of primary xanthoma of bone. 23 cases of temporal bone xanthomas with 2 cases of bilateral xanthoma in a hyperlipidemic patient was reported till 2008 [30,31]. One case of Xanthoma in the occipital bone of the skull in a child with widespread Hodgkin's lymphoma has been reported [7].

Radiologically xanthomas are sharply defined, lytic lesion with an expansile border. Xanthoma can often extend into the surrounding soft tissues, \& because of its aggressive radiologic appearance, it mimics primary bone tumours \& secondary deposits [2]. In our case the patient presented with fracture following fall, radiologically it was multiseptate osteolytic lesion and was thought to be giant cell tumor radiologically. One case of xanthoma in distal tibia with pathological fracture has been reported in literature [7]. Tomoaki Torigoe etal have reported a case with lipoprotein lipase deficiency leading to multiple, symmetrical bone xanthomas associated with hyperlipidemia [30]. Symmetrical involvement in some cases has been reported [31,32]. Surgical Curettage \& bone grafting of the lesion is the treatment of choice, which was also followed in our case.

\section{Conclusion}

In view of the rare intraosseous location with bilaterality in normolipimic individual and with the histology corresponding to a tuberous xanthoma, our case is unique in the sense that our case is first with symmetrical localisation involving tibia and hence this is being presented.

\section{REFERENCES}

[1] F. Bertoni, et al., "Xanthoma of Bone,” American Journal of Clinical Pathology, Vol. 90, No. 4, 1988, pp. 377-384.

[2] P. D. Cruz Jr., C. East and P. R. Bergstresser, "Dermal, Subcutaneous, and Tendon Xanthomas: Diagnostic Markers for Specific Lipoprotein Disorders," Journal of the American Academy of Dermatology, Vol. 19, No. 1, 1988, pp. 95-111. doi:10.1016/S0190-9622(88)70157-7

[3] R. E. Fechner and S. E. Mills, "Tumors of the Bones and
Joints,” In: R. E. Fechner and S. E. Mills, Eds., Armed Forces Institute of Pathology, Washington DC, 1993, pp. 145-171.

[4] H. D. Dorfman and B. Czerniak, "Bone Tumors,” Mosby, St. Louis, 1998, pp. 492-558.

[5] M. Franz, "Enzinger, Soft Tissue Tumours," 3rd Edition, Mosby, St. Louis.

[6] J. Kris, F. Edward and L. Kristy, "Weber, Xanthoma of Bone: A Report of Three Cases and Review of the Literature,” The Iowa Orthopaedic Journal, Vol. 28, 2008, pp. 58-64.

[7] W. C. Hamilton, et al., "Osseous Xanthoma and multiple Hand Tumors as a Complication of Hyperlipidemia. Report of a Case," Journal of Bone and Joint Surgery American Volume, Vol. 57, No. 4, 1975, pp. 551-553.

[8] S. Inserra, et al., "Intraosseous Xanthoma Associated with Hyperlipoproteinemia. A Case Report,” Clinical Orthopaedics and Related Research, Vol. 187, 1984, pp. 218222.

[9] K. Yokoyama, N. Shinohara and K. Wada, "Osseous Xanthomatosis and a Pathologic Fracture in a Patient with Hyperlipidemia. A Case Report,” Clinical Orthopaedics and Related Research, Vol. 236, 1988, pp. 307-310.

[10] L. Algoed, et al., "A Large Intracranial Xanthoma in Familial Hypercholesterolemia," Clinics in Neurology and Neurosurgery, Vol. 96, No. 1, 1994, pp. 79-82.

[11] G. R. Bonhomme, et al., "Extensive Intracranial Xanthoma Associated with Type II Hyperlipidemia,” American Journal of Neuroradiology, Vol. 21, No. 2, 2000, pp. 353-355.

[12] E. T. Elwood, et al., "Isolated Xanthoma of the Frontal Bone,” Journal of Craniofacial Surgery, Vol. 16, No. 3, 2005, pp. 391-394. doi:10.1097/01.scs.0000171963.93992.23

[13] P. J. Emery and M. Gore, “An Extensive Solitary Xanthoma of the Temporal Bone, Associated with Hyperlipoproteinaemia," Journal of Laryngology and Otology, Vol. 96, No. 5, 1982, pp. 451-457. doi:10.1017/S0022215100092707

[14] O. Friedman, et al., "Xanthoma of the Temporal Bone: A Unique Case of This Rare Condition," Ear, Nose, and Throat Journal, Vol. 79, No. 6, 2000, pp. 433-436.

[15] C. F. Huang, et al., "Xanthoma of Bone in a Normolipidemic Child: Report of One Case,” Acta Paediatrica Taiwanica, Vol. 41, No. 3, 2000, pp. 158-160.

[16] R. K. Jackler and D. E. Brackmann, "Xanthoma of the Temporal Bone and Skull Base," American Journal of Otology, Vol. 8, No. 2, 1987, pp. 111-115.

[17] T. Kuroiwa and T. Ohta, A. Tsutsumi, "Xanthoma of the Temporal Bone: Case Report,” Neurosurgery, Vol. 46, No. 4, 2000, pp. 996-998.

[18] M. Matoba, et al., "CT and MRI Findings of Xanthoma in the Orbitofrontal Region,” Radiation Medicine, Vol. 22, No. 2, 2004, pp. 116-119.

[19] P. Kinberg, “Xanthoma of a Calcaneus,” Journal of Foot and Ankle Surgery, Vol. 37, No. 6, 1998, pp. 531-534. doi:10.1016/S1067-2516(98)80031-8

[20] P. Sneider, “Xanthoma of the Calcaneus,” British Journal 
of Radiology, Vol. 36, No. 423, 1963, pp. 222-223. doi:10.1259/0007-1285-36-423-222

[21] U. Yalcinkaya and F. Oztop, "Xanthoma of the Calcaneus Associated with Hyperlipoproteinemia," Journal of the American Podiatric Medical Association, Vol. 95, No. 6, 2005, pp. 602-604.

[22] T. Yamamoto, et al., "Multimodality Imaging Features of Primary Xanthoma of the Calcaneus," Skeletal Radiology, Vol. 32, No. 6, 2003, pp. 367-370. doi:10.1007/s00256-003-0627-z

[23] M. Marques Mateo, et al., "Primary Mandibular Bone Xanthoma. A Case Report,” International Journal of Oral and Maxillofacial Surgery, Vol. 33, No. 8, 2004, pp. 806807.

[24] P. J. Slootweg, J. G. N. Swart and N. Van Kaam, "Xanthomatous Lesion of the Mandible. Report of a Case," International Journal of Oral and Maxillofacial Surgery, Vol. 22, No. 4, 1993, pp. 236-237. doi:10.1016/S0901-5027(05)80644-7

[25] R. D. White and J. Makar Jr., "Xanthofibroma of the Mandible," Journal of Oral and Maxillofacial Surgery, Vol. 44, No. 12, 1986, pp. 1010-1014. doi:10.1016/S0278-2391(86)80058-1

[26] G. S. Huang, et al., "Xanthoma of the Sacrum,” Skeletal
Radiology, Vol. 33, No. 11, 2004, pp. 674-678. doi:10.1007/s00256-004-0829-Z

[27] D. Dallari, et al., "Xanthoma of Bone: First Sign of Hyperlipidemia Type IIB: A Case Report,” Clinical Orthopaedics and Related Research, Vol. 410, 2003, pp. 274277. doi:10.1097/01.blo.0000063790.32430.10

[28] S. Boisgard, et al., "Intraosseous Xanthoma without Lipid Disorders. Case-Report and Literature Review,” Joint Bone Spine, Vol. 47, No. 1, 2000, pp. 71-74.

[29] D. P. Robertson, L. A. Langford and I. E. McCutcheon, "Primary Xanthoma of Thoracic Spine Presenting with Myelopathy,” Spine, Vol. 20, No. 17, 1995, pp. 1933-1937. doi:10.1097/00007632-199509000-00018

[30] T. Torigoe, A. Terakado, Y. Suehara and H. Kurosawa, "Xanthoma of Bone Associated with Lipoprotein Lipase Deficiency,” Skeletal Radiology, Vol. 37, No. 12, 2008, pp. 1153-1156. doi:10.1007/s00256-008-0594-5

[31] K. A. Muthusamy, M. Surg, K. Azmi, M. Rad, et al., "Bilateral Temporal Bone Xanthoma Case Report," Journal of Neurosurg, Vol. 108, No. 2, 2008, pp. 361-364.

[32] D. H. Henick and J. G. Feghali, "Bilateral Cholesterol Granuloma: An Unusual Presentation as an Intradural Mass,” Journal of Otolaryngology, Vol. 23, No. 1, 1994, pp. $15-18$. 